\title{
A human-centric perspective exploring the readiness towards smart warehousing: The case of a large retail distribution warehouse
}

\author{
Bradford University School of Management, University of Bradford \\ Emm Lane, Bradford, BD9 4JL, United Kingdom

\section{Kamran Mahroof} \\ Bradford University School of Management, University of Bradford \\ Emm Lane, Bradford, BD9 4JL, United Kingdom \\ k.mahroof@bradford.ac.uk
}




\begin{abstract}
The explosive rise in technologies has revolutionised the way in which business operate, consumers buy, and the pace at which these activities take place. These advancements continue to have profound impact on business processes across the entire organisation. As such, Logistics and Supply chain management (LSCM) are also leveraging benefits from digitisation, allowing organisations to increase efficiency and productivity, whilst also providing greater transparency and accuracy in the movement of goods. While the warehouse is a key component within LSCM, warehousing research continues to be an understudied area within overall supply chain research, accounting for only a fraction of the overall research within this field. However, of the extant warehouse research, attention has largely been placed on warehouse design, performance and technology use, yet overlooking the determinants of Artificial Intelligence (AI) adoption within warehouses. Accordingly, through proposing an extension of the Technology-OrganisationEnvironment (TOE) framework, this research explores the barriers and opportunities of AI within the warehouse of a major retailer. The findings for this qualitative study reveal AI challenges resulting from a shortage of both skill and mind-set of operational management, while also uncovering the opportunities presented through existing IT infrastructure and pre-existing AI exposure of management.
\end{abstract}

Keywords: Artificial intelligence, Logistics, Warehousing, Technology readiness

\title{
1. Introduction
}

While AI is still in its infancy, its marketing has reached maturity. In general, AI concerns understanding and learning the phenomena of human intelligence and to design computer systems that have the ability to imitate human behavioural patterns and create knowledge relevant to problemsolving (Min, 2010). As a result, the field of AI, Robotics and Machine learning are becoming increasingly pertinent, topical and relevant discussions from within social, academic and industrial settings. As a direct consequence of AI, it is reported the UK GDP will increase by $10.3 \%$ in 2030, equivalent to $£ 232 \mathrm{bn}$ (PriceWaterCooper, 2017), thus making AI not only one of the biggest commercial opportunities in today's fast-changing economy, but also a pertinent and timely topic for academic research. This $10.3 \%$ anticipated growth in GDP is largely projected through improved product quality $(4.5 \%)$, more personalised goods and greater variety of goods (3.7\%) resulting from $\mathrm{AI}$, as well as increased productivity through augmentation of the labour force and automation of some roles $(1.9 \%)$. As a result, the proliferation of AI can be seen as positively influencing the economic outlook for the UK in the foreseeable future.

However, the disruptive impact of AI and automation on employability and job security remains a concern. For instance, it is estimated that 39 to 79 million jobs in the US may potentially diminish as a result of AI and automation, with approximately $20 \%$ of current jobs in the UK also being automated within the same period (McKinsey, 2017). Contrariwise, such indicators and narratives necessitate overview and contextualisation. While it is accepted that technology adoption does cause significant labour stagnation in the short-term, historic trends indicate that in the long term, technology generates a myriad of opportunities, new jobs and triggers demand for existing jobs (Autor, 2015). To illustrate, it is reported that approximately 6\% of all UK jobs in 2013 were such, which were non-existent decades earlier in the 1990's (PriceWaterCooper, 2017). Similarly, a study also found that $0.56 \%$ of new jobs in the United States each year are in new occupations (Lin, 2011), thus implying that $18 \%$ of today's workforce is employed in an occupation that in effect did not exist in the 1980's. Much of this is attributed to the advent of new digital technologies such as computing and communications. Similarly, by the 2030 's, $5 \%$ or more of UK jobs may be in areas related to new robotics and AI, that currently are non-existent.

Unequivocally, the explosive rise in technologies and increasing reliance on information not only influences the choices we make from within social and business contexts, but also impacts how they are made. More specifically, through recognising the significance of information to LSCM success, professionals within this field have explored numerous ways to manage and leverage information for 
decision making purposes. One such way includes AI, which is yet to be fully utilised in the area of LSCM. As such, the focus of this study lies in exploring the potential of AI technology from a LSCM viewpoint, within a distribution warehouse of a major food retailer.

Consequently, by taking a human-centric approach, underpinned by a qualitative orientation, this research focuses more on soft factors, as opposed to traditionally 'hard' factors relating to LSCM. In doing so, the soft factors aim to extend the approach towards understanding how ready the warehouse of a major retailer is to adopt AI technology. This approach is relevant, particularly given that research suggests logistics operations remains a highly human-centred process, displaying high degrees of flexibility and complexity, thus usually resulting in a series of uncertainties (Myers et al., 2004). As a result, the research contributes to the sparse literature that has examined the relationship between key success factors in the form of IT developments and the perceptions of organisational actors from within a logistics context. Particularly as the role and advancements in IT capability and human perceptions from within the warehouse context have not drawn much attention thus far.

\subsection{Rationale}

The extant warehouse literature has provided significant insights into warehouse operations (Gu et al., 2007), its design and performance ( $\mathrm{Gu}$ et al., 2010) and also the role of technologies within warehouses (Hassan et al., 2015). Yet, given that the warehouse is an essential component within LSCM (Hassan et al., 2015) and that warehouse performance has considerable impact on the overall performance of the supply chain, current warehousing research makes up only a fraction of the overall supply chain research, thus presenting opportunities to address many challenging research questions and problems. The motivation of this research is rooted in the fact that there remains a significant gap between published warehouse studies and its practical application; this gap can be attributed to a lack of convergence between practitioners and researchers groups, with either the knowledge produced not being relevant to managerial needs, or being incorrectly transferred (Carter, 2008). Thus, by effectively minimising this gap can help benefit and improve the state-of-the-art in warehouse operations and design methodology (Gu et al., 2010).

Additionally, the extant warehousing literature is largely centred on design and technical factors related to performance, at the expense of human factors (Boysen et al., 2018; Chakravorty, 2009; Dul and Neumann 2009; Grosse et al., 2015; Grosse et al., 2017; Neumann and Dul 2010), while the scant studies addressing human factors has mainly been from an ergonomics and safety point of view (Davarzani and Norrman 2015), and thus neglecting socio-technical aspects. Ryan et al. (2011) also highlight this, emphasising the lack of collaboration between researchers on human factors and operational research, whereby attention towards human aspects in operations management research remains limited (Dul and Neumann 2009; Neumann and Dul 2010). Furthermore, the existing body of warehouse studies also focus on quantitative research methods and mathematical modelling, providing little practical insight without any examples from real cases (Davarzani and Norrman 2015). Accordingly, this research aims to bridge the gap between human factors and warehouse literature by providing real case, practical insights into human aspects from an operational setting through exploring warehouse management and technology adoption. Similarly, while the significant impact resulting from AI is acknowledged (Kshetri 2018), the factors determining AI readiness is an untenanted point of discussion from within warehousing literature. AI solutions may not be easy to implement because they are so esoteric and difficult for ordinary decision-makers to comprehend (Min 2010). Thus, this paper aims to reduce the complexity often associated with technical AI insights by exploring it from managerial, operational lenses. As a result, the overarching aim of this research is to gain an insight into the readiness level of AI through the lenses of warehouse organisational actors. As such, the research questions for this study are: 
1) What are the potential opportunities and barriers for AI adoption in a major retail distribution centre?

\section{2) Does the warehouse have the facilities to operationalise AI technology?}

\section{3) What skillsets does the warehouse operatives have to support AI adoption?}

These questions will guide the research towards gaining an understanding of the organisations technical and human resources capabilities, thus providing a suitable platform to explore technology readiness and adoption from a twofold perspective.

\section{Background}

\subsection{Logistics}

Reverse logistics, Block chain, Green logistics, Internet of Things and Cloud systems are a handful from a plethora of hot topics currently dominating LSCM literature. Yet, in general, the field of technology has continually gained momentum as an academic area of research, from understanding the role of technology, it architectural elements, through to its perceived impact and associated challenges in the workplace. The performance consequences associated with the implementation of IT continues to attract much interest, particularly in light of the continued disruptive nature of technology (Chaysin et al., 2016; Sabherwal \& Jeyaraj 2015). Similarly, recent trends also indicate that the examination of logistics as a field of science which impacts value creation, overall competitiveness of organisations and focuses on the activities of organisations that offer logistical solutions, is both topical and relevant (Olah et al., 2017). Therefore gaining an insight into the overall management success factors that contribute towards logistical competitiveness within organisations is not only necessary, but also a timely topic of discussion (Jazairy et al., 2017; Wu, 2012).

Logistics can be defined as an industry made up of process-oriented businesses centred on managing the flow of material and abstract resources, between a point of origin and point of destination (Chow et al., 2007; Langley \& Holcomb, 1992). While logistics activities extend across the entire supply chain, developing and supporting these activities can improve an organisations overall supply chain performance. The underlying goal of logistics processes are to combine and consolidate all activities related to the acquisition, conversion and distribution of goods, from being in the form of raw materials through to finished goods for customers, so service objectives are achieved in a professional, cost efficient manner (Byrne \& Markham, 1991). Gaining a comprehensive insight into the structure of business processes in LSCM is paramount for the overall success of organisations. Accordingly, it is reported that logistics in its very nature is a human-centred process (Myers et al., 2004; Wang et al., 2014). However, much of what is reported in this regard has predominantly focused on 'hard' success criterion with a quantitative orientation, overlooking the human elements associated with logistics. According to Kowalski et al. (2012) much LSCM focus has been on isolated performance indicators, driven by data, primarily centred on limited quantitative objectives and developed for hard business criteria.

\subsection{Warehousing and technology}

A key feature of logistics is its warehouses, which today, is becoming more and more critical to the overall success and failure of organisations (Frazelle, 2002). The warehouse holds much significance given it plays an intermediary role between various supply chain stakeholders, thus influencing supply chain costs and service (Kiefer \& Novack 1999). Furthermore, in recent times many organisations have taken steps to centralised production and warehouse facilities, in a bid to rationalise supply chain processes and manage them more efficiently (Faber et al., 2013). As a consequence, this has led to the proliferation of larger warehouses in control of distribution to a larger, more diverse customer base, in 
a greater region and, therefore, with more complex internal logistic processes (Kearney, 2005). Due to such significance, the focus from within logistics for this research is in the logistics warehouse.

The utilisation of traditional information and communication technology (ICT) plays a pivotal role in aiding logistical processes (Vieira et al., 2013) and providing visibility across the entire supply chain (Hartono et al., 2010). The extent to which technology is already being operationalised can reflect an organisations readiness to further implement newer forms of technology. Warehousing is at the heart of the logistical system (Aziz et al., 2016), with many technologies being utilised within these settings to ensure products are identified, traced and tracked throughout the warehouse. As such, Logistics intelligence relates to techniques that strive to improve logistical operations, through their capabilities in reducing uncertainties and risks in logistics (Moore, 1990). Building organisations logistic intelligence has attracted much attention (Jedermann \& Lang, 2008; Mejia, 2014).

Currently, a variety of intelligent technologies are commonly used within logistics settings to facilitate logisticians with real-time knowledge (Siror, Huanye, \& Dong, 2011). For instance, multiagent techniques (Chow et al., 2007; Davidsson et al., 2005; Lang et al., 2008) and radio frequency identification (RFID) (Angeles, 2009; Bose \& Pal 2005; Brown \& Russell 2007; Chow et al., 2007; Leimeister et al., 2009; Wen, 2010) are intelligent technologies which provide transparency and enable updates and chains to be controlled intelligently in real-time. Therefore, these technologies play a significant role in facilitating logistics and overall supply chain processes, particularly if supply chain partners also adopt similar technologies, such as RFID (Matta et al., 2012).

Of the key technologies, the role of warehouse management system (WMS) in supporting the warehouse and delivery processes is paramount (Choy et al., 2014; Vijayaraman \& Osyk, 2006). The design of a WMS must consider physical facility characteristics and product movement in order to maximise benefits. Other key warehousing technologies that are widely operationalised include automated storage and retrieval system (AS/RS) (Roodbergen \& Vis 2009), automatic sorting system and computer-aided picking systems (Kim et al., 2016). While the literature reports various technologies that facilitate operations within warehouse settings, in general only a portion LSCM focuses solely on warehouse management (Watson et al., 1999, Rubrico et al., 2008, Chan \& Kumar 2009). Accordingly, table 1 presents some of the key focus from within the warehousing literature. 


\section{Table 1}

Focus of key warehouse literature (adapted Hassan et al., 2015)

\begin{tabular}{|c|c|c|}
\hline Area of focus & Key sub-factors & Writers \\
\hline $\begin{array}{l}\text { Warehouse structural } \\
\text { factors }\end{array}$ & $\begin{array}{l}\text { Warehouse size; } \\
\text { _ number of aisles; } \\
\text { _ number of racks; } \\
\text { _ mechanisation level; } \\
\text { _ departments layout; } \\
\text { _ product carrier of the stock keeping } \\
\text { unit (SKU) } \\
\text { (pallet, case or item); } \\
\text { _ product type; } \\
\text { _ temperature; } \\
\text { _ humidity; } \\
\text { _ noise; } \\
\text { _ dust and dirt; } \\
\text { - pressure; } \\
\text { - E-Plane (electric field); } \\
\text { _ H-Plane (magnetic field). }\end{array}$ & $\begin{array}{l}\text { De Koster et al., 2007; Gu et al., 2010; Arooj et al., 2011; Bhuptani and } \\
\text { Moradpour 2005; Karagiannaki et al., } 2011 \text { Venkitasubramony and Adil 2017; } \\
\text { Derhami et al., 2017:2016; Boysen et al., } 2017\end{array}$ \\
\hline $\begin{array}{l}\text { Warehouse operational } \\
\text { factors }\end{array}$ & $\begin{array}{l}\text { Receiving } \\
\text { _ put away } \\
\text { _ forward reserve allocation } \\
\text { _ picking } \\
\text { _ order accumulation and sorting } \\
\text { - zoning } \\
\text { _ batching } \\
\text { _ routing } \\
\text { _ shipping } \\
\text { _ storage assignment policy. }\end{array}$ & $\begin{array}{l}\text { Rouwenhorst et al., 2000; Gu et al., 2007; Karagiannaki et al., } 2011 \\
\text { Coyle et al., 1996; Tompkins et al., 2003; De Koster et al., } 2007 \\
\text { Pan et al., 2011; Chan and Cheng 2012; Korobkov, } 2014\end{array}$ \\
\hline Resource factors & $\begin{array}{l}\text { Storage units } \\
\text { _ storage systems } \\
\text { - warehouse management system } \\
\text { - material handling equipment } \\
\text { _ warehouse staff members (labour) } \\
\text { _ storage space capacity }\end{array}$ & $\begin{array}{l}\text { Rouwenhorst et al., 2000; Karagiannaki et al., 2011; Mishra et al., 2011; Chan } \\
\text { and Chan 2011; Lee et al., 2018; Machado and Sellitto, 2011; }\end{array}$ \\
\hline Organisational factors & $\begin{array}{l}\text { Top management support } \\
\text { _ IT knowledge capability }\end{array}$ & $\begin{array}{l}\text { Hwang et al., 2004; Liviu et al., 2009; Laosirihongthong et al., } \\
2013\end{array}$ \\
\hline
\end{tabular}


Technology factors

External factors
Warehouse internal needs.

Technology costs

_ deployment costs

- line-of-sight; labour

- visibility

- accuracy

- reliability

item level tracking

_ traceable warranty

product recalls

- quality control

_ tag data storage

_ information properties

_tag weight

_ tag read/write capabilities

operational life

- memory

communication range

- multi-tag collection

- security

privacy

- environmental sensitivity

interference

ongoing innovations

_ ease of use

- established standards

performance

- Return on Investment (ROI).

Big data

Government pressure;

competitive pressure;

customer pressure;

- Technology provider support.
Huber et al, 2007; Sarac et al., 2010; Poon et al., 2011; Kumar et al., 2011; Żuchowski 2016; Govindan et al., 2018;

Hwang et al., 2004; Wang, Wang, and Yang 2010; Quetti, Pigni, and Clerici (2012) 
It has previously been reported that approximately 750,000 or more warehouse facilities exist worldwide (Lambert et al., 1998), two decades on; this number is only expected to have increased exponentially. Warehouses are principally made up of processes, resources and structure (Karagiannaki et al., 2011). Goods which arrive at a warehouse undergo various activities. Thus, it is argued that for almost every warehouse, the single most labour-intensive and costly activity is order picking (Tompkins et al., 2003). Order picking involves responsively retrieving products from allocated storage areas for specific customer requests. It is estimated that this warehouse operation contributes up to $55 \%$ of the entire warehouse operating cost. Therefore, it is argued that order picking deficiencies has a profound impact, not only on service, but also on overall operating costs and the entire supply chain. As a consequence of these underlying factors, order picking is regarded as the main priority focus for productivity improvements (De Koster et al., 2007). Accordingly, this research aims to focus primarily on AI for the purposes of order picking within the warehouse context. The underlying requirement for warehouse automation arises from potential human errors caused as a result of manual handling, thus leading to warehouse and overall logistical inefficiencies (Seifermann et al., 2014). Figure1 reflects the typical operational processes in a warehouse and the proposed AI automation for this study.

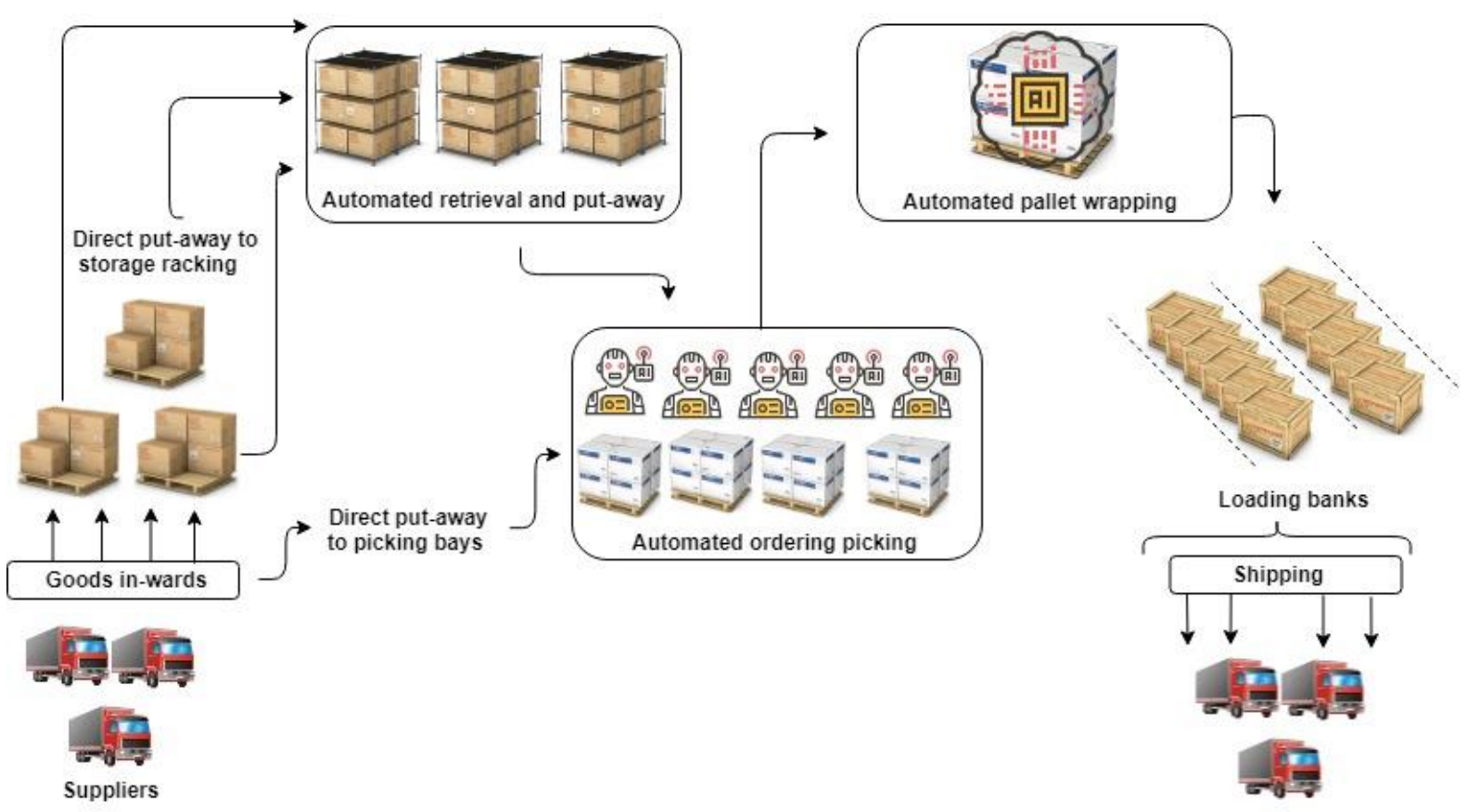

Fig 1. Proposed warehouse AI automation

The amalgamation of innovative technologies, newer IT architectures, big data and analytics presents an array of opportunities, certainly in the world of LSCM, whereby their proliferation can achieve highly linked, flexible, well-organised end to end supply chains, responsive to the needs of relevant stakeholders (Porter \& Heppelmann 2015). The implementation of digital technologies and complex data-rich systems allows the supply chain to become considerably efficient is one thing (Khajavi \& Holmström, 2015), however a more drastic proposal is one in which such advancement have such profound impact which results in completely new production, business and operating models. From a warehouse perspective, the use of AI technology certainly presents such radical changes to the operating design and model of the warehouse.

Technology is now playing a leading role in aiding logistical processes, however, while the extant literature relating to warehouse technologies is well founded, only a handful of studies have explored 
the potential for AI technology and its implications within warehouse contexts (Chincholkar et al., 1994; Curry et al., 2003; Hsieh et al., 1998; Knapp \& Wang, 1992; Seidmann, 1988) yet there seems to be an emergent relationship between warehousing and AI (See 3.0). Therefore, in spite of the extant literature highlighting the opportunities presented through leveraging technology within logistics, a vacant discussion remains in relation to the readiness of a major retailer's warehouse towards AI adoption, from a human-centric perspective.

While it is widely accepted that innovation and performance in logistics industry have a direct relationship (Flint et al., 2005; Ho \& Chang, 2015; Yang et al., 2009), there remains a wider and highly pertinent question concerning the adequacy of both digital skills and attitudes at management levels, both middle and senior and certainly those within operational settings, such as the warehouse operatives. Although organisations may be committed to the opportunities presented through acquiring technology on a strategic level, a potential shortage of both skills and mind-set creates a major obstacle in exploiting the opportunities presented through digitalisation within LSCM (Hennelly et al, 2017). Therefore this research also aims to address this shortfall by also investigating whether the warehouse management are amply equipped to implement AI within their logistics operations.

While technological innovation has great potential for LSCM and quick response systems (Zhu et al., 2012), the exploitation of new technologies has always been and continues to be a procedure of social negotiation by nature, with its success largely dependent on stakeholder acceptance and participation. The proliferation of email use and internet capabilities can be regarded as somewhat breakthrough technological innovations, which were both effectively deployed and managed within the work place. While many of us are privy to AI and machine learning in our daily lives through machine translation, speech recognition, image classification and information retrieval, its deployment in organisations is marred by many challenges (Holtel 2016). Table 2 presents taxonomy of AI challenges. 
Table 2

AI challenges

\begin{tabular}{|c|c|c|}
\hline Barriers & Description & Authors \\
\hline Hardware challenges & $\begin{array}{l}\text { There is on-going research on modifying the machine } \\
\text { learning algorithms to make them more hardware-friendly } \\
\text { while maintaining accuracy; specifically, the focus is on } \\
\text { reducing computation, data movement and storage } \\
\text { requirements. }\end{array}$ & Jawandhiya, 2018; Sze et al., 2017 \\
\hline Mission critical AI & $\begin{array}{l}\text { Design AI systems that learn continually by interacting with a } \\
\text { dynamic environment, while making decisions that are } \\
\text { timely, robust, and secure. }\end{array}$ & Stocia et al. (2017) \\
\hline AI across organisations & $\begin{array}{l}\text { Design AI systems that can train on datasets owned by } \\
\text { divergent organizations without compromising their } \\
\text { confidentiality, and in the process provide AI capabilities that } \\
\text { span the boundaries of potentially competing organization. }\end{array}$ & Stocia et al. (2017) \\
\hline $\begin{array}{l}\text { AI demands outpacing the } \\
\text { Moore's Law }\end{array}$ & $\begin{array}{l}\text { Develop domain-specific architectures and software systems } \\
\text { to address the performance needs of future AI applications in } \\
\text { the post-Moore's Law era, including custom chips for AI } \\
\text { workloads, edge-cloud systems to efficiently process data at } \\
\text { the edge, and techniques for abstracting and sampling data. }\end{array}$ & Stocia et al. (2017) \\
\hline Personalised AI & $\begin{array}{l}\text { Design AI systems that enable personalized applications and } \\
\text { services yet do not compromise users' privacy and security }\end{array}$ & Stocia et al. (2017) \\
\hline Energy consumption & $\begin{array}{l}\text { Computing energy consumption, given the pace and speed of } \\
\text { processing }\end{array}$ & M. Horowitz (2014) \\
\hline Insufficient training data & $\begin{array}{l}\text { Either the training data set is too small to learn a } \\
\text { generalizable model or the data are a skewed sample that } \\
\text { does not reflect the true underlying population distribution. }\end{array}$ & Brodley et al. (2012) \\
\hline Integrating unstructured text & $\begin{array}{l}\text { Challenge is the task is to build up knowledge bases (or } \\
\text { knowledge graphs) that can enable and contribute to } \\
\text { intelligent applications, such as semantic search, question } \\
\text { answering, or even reasoning and large-scale machine } \\
\text { reading. }\end{array}$ & Zhuang et al. (2017) \\
\hline Stakeholder buy-in & $\begin{array}{l}\text { Firm should involve all relevant stakeholders into initial stage } \\
\text { of deployment as the impact of AI is far reaching. }\end{array}$ & Holtel (2016) \\
\hline Disruption to working pattern & $\begin{array}{l}\text { All employees will be affected by AI, the way in which they } \\
\text { work, the way they make decisions, or the predictions and } \\
\text { forecasts. }\end{array}$ & Holtel (2016) \\
\hline
\end{tabular}


Restructure of knowledge work

Balance of power

Force cognitive literacy

Psychological and societal

impact

Productivity paradox

False hope

Mismeasurement

Concentrated distribution

Implementation

restructuring lags

Design and layout

Skills
Cognitive tools, reshape and redefine the way of knowledge work as we may know it

Some with make better use of it to pursue their goals whilst other won't

Employee's within an organisation will be forced into enhancing their cognitive literacy, regardless of their current level of cognitive competence

AI may not achieve the productivity gain expected, because companies do not know how to exploit them

Optimism about the potential technologies is misplaced and unfounded. Perhaps these technologies won't be as transformative as many expect, and aggregate impact may be small

Mismeasurement of output and productivity. Although productivity benefits of the new wave of technologies are already being enjoyed but have yet to be accurately measured.

Both those seeking to be one of the few beneficiaries, as well as those who have attained some gains and seek to block access to others, engage in these dissipative efforts, destroying many of the benefits of the new technologies.

and It takes a considerable time often more than is commonly appreciated to be able to sufficiently harness new technologies.

designing the warehouses a balance between flexibility, Lerher et al. 2010

layout configuration, storage density and throughput capacity in order to achieve an effective design at a minimum cost have to be achieved

The underlying question whether operational staff and Hennelly et al. 2017 management are adequately equipped to implement digitalisation throughout their operations and supply chain?
Holtel, 2014; Holtel, 2015

Holtel, 2016

Holtel, 2016

Brynjolfsson et al. 2017; David, 1990

Brynjolfsson et al. 2017

Brynjolfsson et al. 2017

Brynjolfsson et al. 2017; Stiglitz, 2014

Brynjolfsson et al. 2017 


\section{Logistics \& Machine learning cases: An emergent relationship}

Advancements in technology continue to reach new heights. As we enter the new automation age, industrial robots and computers are now being used beyond their traditional scope of performing highly accurate repetitive tasks, routine physical work tasks, through to more complex tasks that require cognitive capabilities such as making tacit judgements, sensing emotion and driving processes which previously seemed impossible. While robots and computation have long been associated from manufacturing and production contexts, these forms of technologies are increasingly finding their place within LSCM contexts.

In order to sustain profitability and meeting customer's requirements of quality and price, it is imperative to be aware of how to improve logistics processes (Džubáková \& Kopták 2017). Internal logistics exploits labour and machine work through utilising technology at different levels of mechanisation and automatisation such as loading and unloading materials, transportation, and warehousing. Of the many organisations proactively pursuing innovative warehouse practises, ecommerce giants, Alibaba are leading the way, exploring the opportunities presented by technology through AI and machine learning to optimise its LSCM. Alibaba's increasing commitment to machine learning and automation is evident through what is regarded as China's largest smart warehouse. The smart warehouse is equipped with 60 robots, known as 'Zhu Que' or the 'Vermilion Bird', which are tasked with $70 \%$ of warehouse processes (Pickering, 2017). These robots are reported to have achieved a threefold increase in output as a result of their Wifi-equipped, self-charging batteries and laser detection technology preventing collision across their 3,000 square metre warehouse.

However, in the world of robotics and warehouse automation, the sky is (literally) the limit for French robotics company, Exotec Solutions. The AI specialist have developed warehouse robots that automate High level order picking (HLOP) by climbing up warehouse racks, picking orders and transporting them to warehouse operatives, in the process picking up to 400 orders an hour. The robots, known as 'Skypod' use AI and laser scanner navigation to process orders and are currently operational with one French online retailer (Pickering, 2017).

From within the UK, E-commerce grocery chain and retailer partners Ocado continue to strive for innovative excellence, with a fully automated warehouse into full service and further plans to unveil a second automated warehouse. The warehouse is designed to have no aisles and is filled below the ceiling height with inventory, as a result Ocado have significantly reduced their human workforce by investing in hundreds of robots that works above the stacks of inventory, digging down to pick boxes and transport them to human warehouse operatives (Ocado, 2018).

It is therefore evident that machine learning, automation and AI are now increasingly finding a place within warehousing and logistical distribution centres. Yet, it is well known that logistics is an exceedingly human-centred process, consisting of high dynamics and complexities. Further emphasising this human emphasis, studies report most decisions are made by human experts with varying kinds of hands-on experiences in the logistics processes (Chow et al., 2005, 2007). Therefore, this study attempts to negotiate the dyadic relationship between advancements in technology and human capital.

\section{Research Methodology}

This case study research utilises a qualitative approach, particularly as an increasingly number of studies are opting for this type of research within LSCM (Cullen et al., 2013; Huemer, 2012; Varoutsa and Scapens 2015; Wagner and Sutter 2012). Accordingly, logistics as a field of research is undergoing a trend towards more naturalistic, interpretivist type research associated with qualitative methods (Halldórsson and Aastrup, 2003). The motivations for a single case study approach were 
underpinned by the fact that this approach provides an in-depth description of the existence of phenomenon (Siggelkow 2007), which is also favoured when studying a group of people (Yin 2003), such as key warehouse managerial actors. Case study is appropriate for the purposes of this research, particularly as case studies can be used to help develop an understanding of deep-rooted organisational issues associated to IT benefits realisation (Dhillion 2005). Additionally, the single case research is also recognised for its descriptive power and attention to context (Shakir 2002), with these elements being vital in the context of this research. Single case studies provide reliable indications of future research, whilst providing new, deep and nuanced understanding of previously unexplored phenomena (Boddy 2016). As a result, this case study research is supported by interpretive methods, particularly as the aim of interpretivism is to provide insights of a given phenomenon (Sachan \& Datta 2005). The aim of this research is to gather information from subjective representations of interviewees which mirror the phenomenon being studied, which in this research context is technology and human interpretations relating to it.

\subsection{Methods}

The focus of this research is to explore the readiness of AI warehousing technology from a humancentric perspective, through the lenses of warehouse operational staff and management. As such, the research makes use of semi-structured interviews as this is suitable for studying human behaviour and behavioural changes, thus the intricacy related to technology attitudes, adoption and use can be meritoriously explored through qualitative lens. Additionally, qualitative orientations are appropriate for extracting people's interpretations of technologies and their actions around them (Orlikowski \& Gash, 1994). The key focus of this research is on attitudes regarding AI technology; therefore this approach is highly suited. Interpretivism is the philosophical basis for this research, as it endorses indepth insights, while also detecting fundamental values and attitudes which are essential, given the human-centric, soft focus of this research. The conceptual framework consisting of key theoretical constructs will be applied to help guide the enquiry during the interviewing and analysing processes.

This research focuses on various organisational actors from within the warehouse at the case organisation, in doing so 8 semi-structured interviews were conducted with operational staff in a variety of roles and seniority, as highlighted in table 3 . In order to recruit the participants for this research, an exponential non-discriminative snowball sampling approach was used (Etikanet al., 2016). As a consequence, every research volunteer recruited another volunteer for the research. However, the initial research volunteer was recruited through the professional connections of the researcher.

Table 3

Research participant profiles

\begin{tabular}{|c|c|c|c|}
\hline $\begin{array}{l}\text { Participant } \\
\text { (Gender) }\end{array}$ & initials & Role & $\begin{array}{l}\text { Operational } \\
\text { experience (Years) }\end{array}$ \\
\hline S.A (male) & & Shift operational manager & 24 \\
\hline P.H (male) & & Shift operational manager & 15 \\
\hline S.H (male) & & Technology manager & 17 \\
\hline M.B (male) & & Team manager & 7 \\
\hline A.H (male) & & Shift operational manager & 8 \\
\hline R.B (male) & & Shift operational manager & 4 \\
\hline P.C (male) & & Implementation manager & 8 \\
\hline A.A (female) & & Project manager & 3 \\
\hline
\end{tabular}


The main motivations for the interview framing were provided from technology adoption literature (Baker et al., 2012 Oliveira and Martins 2011; Tornatzky \& Fleischer, 1990) as well as sociotechnical literature (Klump 2018; Kolbjørnsrud et al., 2017; Lee et al., 2014) which explored various dimensions of technology readiness. The semi-structured interviews consisted of 8, open-ended, exploratory questions gleaned from relevant academic sources. Accordingly, as the research focuses on attitudes concerning AI technology, the interview schema addressed key aspects (outlined in Table 4) from firm level; technology, organisational factors, environmental factors and perceived benefits for the organisation. Given the open-ended, semi-structured nature of the interview questions, additional themes were also discussed.

Qualitative thematic analysis was used to analysis the data, with the specific aim of exploring the research questions, whilst also allowing for unexpected insights to surface from the data (Klein and Myers 1999). This analytical approach consisted of data transcription, data coding and analysing, and due to its flexibility is considered a highly beneficial analytical approach. Thematic analysis was deemed appropriate for this study as it offers rich and highly detailed, yet multifaceted accounts of the data (Braun and Clarke 2006), thus allowing for many themes of the research to be interpreted (Boyatzis, 1998). All the interviews were formal, semi-structured and were conducted within the warehouse offices, on a one to one basis. Ethical approval was granted by the University of Bradford, School of Management. In upholding anonymisation, the participants' names were replaced with their initials in the study.

\section{Conceptual framework}

Technologies continue to advance, evolve and disseminate, thus perpetually driving technology adoption and users acceptance discussions, while also continually presenting challenges from a management context (Schwarz \& Chin 2007). Consequently, a plethora of models, theories and frameworks have been propagated over the years to help understand the dyadic relation between technology and organisational acceptance. Of the many, it is widely accepted that the technology acceptance model (TAM) (Davis, 1986), and its subsequent developments (Venkatesh \& Davis 2000; Venkatesh \& Bala 2008), theory of planned behaviour (TPB) (Ajzen, 1985), diffusion of innovation (DOI) (Rogers, 1995) and TOE (Tornatzky \& Fleischer, 1990) are key theories in this field. Given the overabundance of models, Venkatesh et al., (2003) developed a unified model, The unified theory of acceptance and use of technology (UTAUT) that connects the divergent views on user and innovation acceptance. Williams et al., (2015) performed a systematic review of articles that used the UTAUT model, highlighting it as a favoured model for examining general purpose systems and specialised business systems. The UTAUT model has recently been enhanced and found to perform better through incorporating the attitude construct an integral part of the model, given the given the role of attitude in behavioural intention (Dwivedi et al., 2017).

While these theories assist in our understanding of technology acquiescence, they offer differing focus from various perspectives. For instance, while the TOE and DOI have a firm level focus, the UTAUT, TPB and TAM models are centred on more of an individual level (Oliveira and Martins 2011). Conceptually, this research adapts a firm level focus, predominantly as the purpose is to establish a large distribution centre's readiness to adopt AI. Nonetheless, the firm level focus will be explored through the lenses of various members of management from within the warehouse.

Consideration should also be given to the types of technology when deciding which model to utilise. For instance, the theoretical constructs from the aforementioned models may be more, or less applicable given the nature, orientation and complexity of the technology in question. Therefore, in line with the approach of Venkatesh et al., (2003), combining more than one theoretical model may help achieve a better understanding of the IT adoption phenomenon (Oliveira et al., 2011). Combining theories to understand IT adoption is well evidenced within the extant literature, (Gibbs \& Kraemer 2004; Hsu et al., 2006; Oliveira and Martins 2010, Zhou et al., 2010). Thus, given the complexity associated with AI adoption, this research in line with Kuan and Chau (2001) proposes to combine the key theoretical constructs of the TOE framework (Tornatzky \& Fleischer, 1990) and Iacovou et 
al.(1995) models (Fig.2) to explore AI readiness. Accordingly, based on the existing literature and drawing upon the research questions, this study presents the following proposition to address the readiness for $\mathrm{AI}$ adoption by the case company:

Proposition: The proposed TOE framework extension provides ideal lenses to explore AI readiness within a warehousing context.

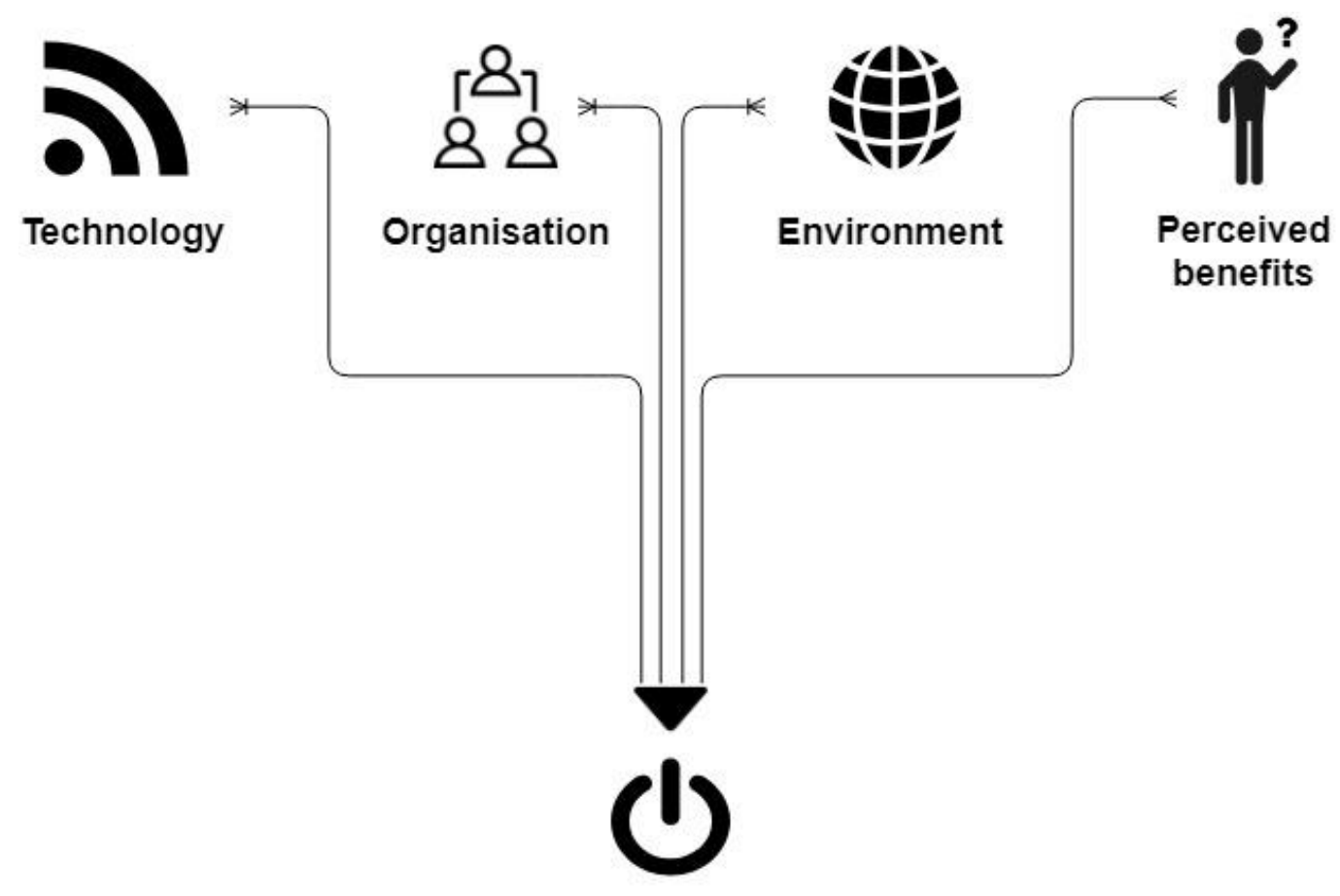

Al adoption

Fig.2 Conceptual framework

Figure 2 highlights many-to-one relationships between various elements from within technological, organisational, environmental contexts and the adoption of AI technology, whilst also considering its various perceived benefits. Accordingly, the key theoretical constructs for this research are highlighted in table 3. The Iacovou et al., (1995) model consists of 'perceived benefits, organisational readiness and external pressures'. However, for the purposes of this research, only the 'perceived benefits' construct from the Iacovou et al., (1995) model will be integrated into the TOE model as the 'organisational readiness and external pressures' constructs are encompassed within the TOE model. Baker (2012) supports this compatibility by highlighting that the Iacovou et al., (1995) model is gradually becoming incorporated into the body of TOE research, thus the 'perceived AI benefits' will refer to the level of recognition of the relative advantage that AI technology can provide the organisation. Previously, Chau and Tam (1997) also utilise the TOE model and incorporate perceived benefits in their exploration of open systems adoption. Thus, subsuming aspects of these theories has been found to be useful in understanding the adoption of technological innovations.

According to Baker (2012), the TOE framework is regarded as being highly apt, given the frameworks freedom to vary the factors or measures for each new research context, accordingly, Baker (2012) presents an overview of the TOE framework and its adaption by a plethora of authors from varying research contexts. Aboelmaged (2014) utilises the TOE framework to explore ereadiness at firm level, more recently, Jia et al., (2017) explores information systems continuance 
using TOE, whereas Kim and Garrison et al., (2010) has also utilised the framework to explore users' behaviours regarding supply chain technology. From an organisational context, TOE provides a suitable framework through which technological, organisational and environmental contexts are analysed from a technology adoption context. Given that the case organisation is already operationalising AI technology within their supply chain (see 5.0), the TOE framework is useful in identifying technological, organisational and environmental factors and external and internal attributes which may impact AI adoption from within the distribution warehouse context in this research. 
Table 4

Theoretical constructs

\section{Construct [Model]}

Technology [TOE]

Organisation [TOE]

Environment [TOE]

Perceived benefits [Iacovou et al., 1995)

\section{Definition}

Considering the available technologies important to the firm,

both internal and external, that may be useful in improving

organisational productivity

Resources available to support the acceptance of the innovation

[including firm size, scope; managerial structure; human

resources capabilities

External influences in the form of Industry, competitors, firms

ability to access resources supplied by others

Perceived benefits refer to the level of recognition of the

relative advantage that AI technology can provide the

organization

\section{Provenance}

Tornatzky and

Fleischer (1990)

Tornatzky and

Fleischer (1990)

Tornatzky and

Fleischer (1990)

Iacovou et al., Firm Level

(1995)
Firm Level

Firm Level 


\section{Case company: Large food retailer}

In order to survive and remain competitive in an ever growing global market, managing the future is paramount (Patro \& Raghunath 2015). Technology is a realistic pathway to achieving this. According to PriceWaterCooper (2017), by 2030's, the transportation and storage industry will experience approximately $56 \%$ automation, with wholesale and retail also being forecasted high at $44 \%$. Although, studies reveal that AI adoption outside of the tech sector is at an early, often experimental stage, with only a handful of firms deploying AI technology at scale (McKinsey, 2017), the case examples provided previously (Alibaba, Exotec, Ocado) highlight how IT and specifically AI automation can drastically assist in restructuring the entire distribution set up to achieve higher service levels and lower inventory and logistics costs.

Similarly, the case company have also taken major strides towards utilising technology advancements and AI as part of their logistic and supply chain processes. The company has recently enjoyed a growth in annual profits, with a reported increase in like-for-like sales. Much of this success is attributed to leading-edge machine-learning technology which has transformed the companies' forecasting abilities and automated its replenishment processes, thus significantly impacting the overall logistical processes. The case company, through their partnership with a major AI and machine learning specialists have launched an innovative, ordering system capable of automatically analysing historic sales data and other internal data sources, combined with external data such as weather forecasts and public holidays.

This AI technology, through its algorithms allows the company to predict the level of demand of every product for each store location, triggering a process that automates millions of decisions on a daily basis, balancing multiple and competing KPIs, to enhancing availability while reducing waste and significantly minimising shelf gaps. While many companies are utilising AI within the warehouse context as previously discussed, the case companies entire logistic operations are impacted by this AI technology, which conversely, is utilised at the start of their logistic operations. This operational transformation at the heart of its business plays a major role in determining the nature, pace and demand of operations in the case companies' distribution warehouses across the country (Fig.3). 


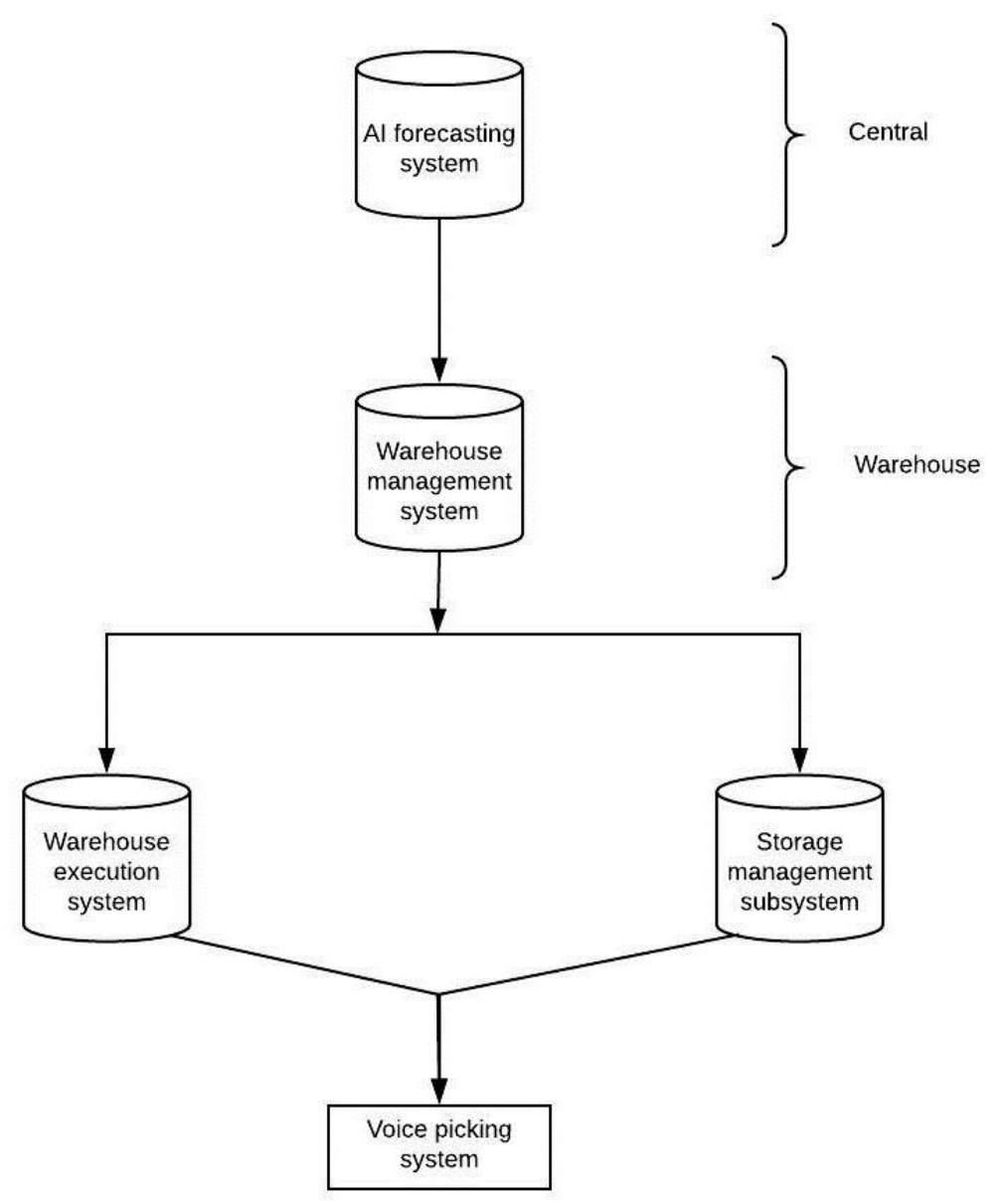

Fig 3. Case companies existing AI system

What makes the case company unique and an increasingly favourable case for this research is, firstly their adoption, commitment and current success resulting from AI and machine learning technology. Additionally, the case company is also in a vital partnership with innovation specialists, whom manages and maintains the online shopping service for the case company from their smart warehouse. This partnership is lucrative to both parties, however the extent to which the case company can follow in the technological, logistical and innovative practices of their innovation partners and the implications of such moves is a highly pertinent and relevant point of discussion.

$\mathrm{AI}$ and Machine learning serve a plethora of purposes, yet ultimately play a critical role in extracting meaningful information out of the zettabytes of sensor data collected daily. Yet for some AI applications, the purpose is solely to analyse and interpret vast datasets in order to identify trends (e.g., surveillance, portable/wearable electronics). Whereas, other forms of AI are tasked with taking immediate action based the data (e.g., robotics/drones, self-driving cars, smart Internet of Things) (Sze et al., 2017). Currently the case company are utilising the former, whereby their AI ordering systems helps identify sales trends and thus triggers order picking figures for distribution on a daily basis.

\section{Findings}

The analysis revealed a plethora of insights regarding AI, as well as other forms of technology within the warehouse environment. The key themes derived from the analysis are summarised in table 5 . however it was evident from the analysis that AI operations has the potential within the case 
warehouse. However, many barriers to AI implementation also surfaced, as will be highlighted further. The senior implementation manager stated; 'From the top, there is an absolute desire, as a direction for the business to go.' The implementation manager refers to the ambition of high-level, senior management in committing towards this technology. These sentiments are a reflection of the organisations currently archaic, out-dated operations, as supported by the following statement, 'We know... that we have really pushed the boundaries of how far we can go with our current ways of working and technology.' It is due to these factors, that this research explores the technology readiness level of this organisation.

\section{Table 5}

Key findings 


\begin{tabular}{|c|c|c|c|c|}
\hline \multirow{2}{*}{ Opportunities } & Technology & Organisation & Environment & Perceived benefits \\
\hline & $\begin{array}{l}\text { WMS and other systems } \\
\text { Integration capability }\end{array}$ & $\begin{array}{l}\text { Deploy } 3^{\text {rd }} \text { party to manage AI and } \\
\text { its glitches } \\
\text { Role of AI exposure } \\
\text { On-site specialists }\end{array}$ & & $\begin{array}{l}\text { Improve service level to customers in form } \\
\text { of punctuality and accuracy } \\
\text { Drive accuracy and visibility }\end{array}$ \\
\hline Barriers & $\begin{array}{l}\text { Operational management } \\
\text { limited understanding of } \\
\text { existing infrastructure } \\
\text { Managing the assets } \\
\text { Compatibility of systems } \\
\text { and assets } \\
\text { Maintenance of } \\
\text { technology }\end{array}$ & $\begin{array}{l}\text { Limited foresight of technological } \\
\text { roadmap } \\
\text { Lack of transparency between } \\
\text { strategy-makers and the warehouse } \\
\text { management } \\
\text { Skill-set and mind sets of } \\
\text { operational managers } \\
\text { Current pool of management have } \\
\text { limited AI exposure } \\
\text { Change management required } \\
\text { across the warehouse } \\
\text { Flow and structural challenges } \\
\text { Layout is dated and not AI friendly }\end{array}$ & $\begin{array}{l}\text { Competitors } \\
\text { Internal tensions, resulting } \\
\text { from potential redundancies } \\
\text { Pressure on other areas of } \\
\text { operation, such as transport } \\
\text { Trade union pressure } \\
\text { Silo mentality }\end{array}$ & \\
\hline
\end{tabular}




\subsection{Technology}

7.1.1 'What we're putting in place is a facilitator, should the business move towards AI.' - Preparing for the future

The technological characteristics and existing infrastructure of an organisation play a vital role in adopting emerging technologies. The organisation currently has AI solutions in place, such as their forecasting and finance tools, thus potentially allowing for AI to make an easier transition into the warehouse. The project manager posits: 'We've built the comms of the interfaces into (central) forecasting and finance tools, so it's less of an upheaval and becomes a localised change in the warehouse as opposed to a business change'. Furthermore, M.B highlighted the role of the existing AI tool, when stating 'before the forecasting system came in, there would have been a room of 100 people all trying to work out what each store wants.' Thus highlighting that the technology readiness level is significantly influenced by an organisations ongoing technological commitment.

It was revealed that while the warehouse has many challenges, the potential for AI adoption is a realistic option in the near future. The technology manager, S.H outlined: 'We don't have blockers, we have steps and phases of where we have to go to where the roadmap is taking us.' He mentioned that while AI adoption in the warehouse may be in the distant future, the key for him was to ensure if the organisation decided to go in that direction, that the technical architecture and infrastructure was in place to support it. This was further emphasised by another member of the implementation team: 'First big step is the warehouse management system to bolt all this AI onto'. Therefore, ensuring that the technical infrastructure is in place is fundamental for potential AI.

The technology and implementation team expressed their optimism regarding AI which can be attributed to their skill-base and understanding the scope of the current technology in the warehouse: 'Its levels, everything we're putting in place are a facilitator for AI.' The implementation teams understand what is required to phase in AI in the future, however, attitudes from operational managers, differed. This can be seen here, when team manager, D.H outlined: 'With the technology we've got in place, the warehouse is not ready. The systems are a long way behind what would be required.' There seems to be very little understanding from the operational staff regarding the potential of the current systems and how they have the ability to 'talk with AI'. This is further witnessed here when M.B, sarcastically posits: 'We've only just moved from the big tin in the corner, to cloud hosting', thus implying that embracing $\mathrm{AI}$ is out of the question.

On the contrary, the project manager outlined: 'we can still manage AI through our new our existing infrastructure, except instead on directing tasks to people, it would direct tasks to automation'. The disparity between the technical experts and the operational management can be further seen when P.C, the senior implementation manager and M.B, a team manager discussed picking by paper. M.B, states: 'When we picked on paper, we'd have more flexibility.. We have to rely on the technology to work; sometimes it crashes and puts us behind!' In contrast, P.C mentions: 'Picking on paper very rarely see accident coming, the crash has already happen so how do you deal with that, the system gives you the visibility to see the accident happen before it does and being proactive.' Therefore, the views pertaining to technology in general between various organisational actors are influenced by their role, with the warehouse managers driven by operations and metrics during their shifts, whilst the implementation team exercise more prudence and farsightedness.

Notwithstanding, the implementation team acknowledge that a warehouse move to AI would be challenging from an asset management perspective. P.C highlights: 'There becomes a whole asset management discussion, where does stuff go? If that isn't enough, you have to go and look at health and safety etc'. Similarly, S.A expresses 'if a truck breaks down, we'll strip it and fix it, but if a robot, or complex machine does, how quickly can we resume operations? Therefore, beyond the technology and infrastructure, assets management and maintenance are also key considerations. 
7.2 Organisation

\subsection{1 'Only so much of the road you have visibility of' - Executive management influence}

The resources available to an organisation play a vital role in the adoption of technology; these include managerial structure, linking structures and communication process. Accordingly, it was evident from the insights that executive management were drivers of the initiatives for the warehouse and the organisation as a whole. For instance, the senior implementation manager mentioned: 'Roadmap comes from on high, so all the really seniors in every vertical, so from IT, from infrastructure, whatever they all work together and they have an idea of where we need to be.' Therefore, the readiness of the warehouse to embrace any form of technological change requires the support and acceptance firstly from the senior management.

However, there also seemed to be a lack of transparency between the strategy-makers and the warehouse management. This was also reflected by the implementation manager: 'bomb door opens and out drops the bomb, it's like okay, and we need to deal with this now.' Here, the implementation manager refers to the bomb doors as the 'go ahead' and the 'bombs' as projects that requires implementing within the warehouse. This indicates that projects may frequently require implementation on tight timescales, with limited prior notice, or that the projects may be beyond the scope of the warehouse, as further highlighted: 'There'll be stuff on that roadmap we don't know about yet, but we will be told what we need to work towards.' Therefore, the role of the organisation, particularly senior management can also be considered vital for AI adoption.

\subsection{2 'Management peddle really really quickly, but forget to steer' - Human resources capabilities}

The skill-sets of warehouse operators and management were also highlighted as a key factor in AI adoption. One of the shift operational managers' highlights that skills within the warehouse were more operationally orientated rooted in old-fashioned ways of working as opposed to being technical. Therefore, the adoption of AI would be disruptive. A.H posits: 'We are of a few places left that have a remarkable record on staff retention; we have people with up to 20-25 years' service. So it's a massive step'. Although the manager was referring to the operational workforce, it was evident that upskilling was also required by the warehouse management. A project manager recollects the chaotic nature in which new technology and new ways of working has previously been put into practice within the warehouse: 'everybody is so focused on the new ways of working that they peddle really really quickly, but forget to steer'. Thus highlighting that warehouse management place more effort than required, therefore lacking direction in the process. Furthermore, P.H, while recollecting his AI experiences from previous employment states: 'Permanent AI team onsite is a must, as in my previous work there'd be a Dematic team on site, all the time'. Hence, while there is a shortfall of AI skillssets from within the warehouse, third party specialist may be an avenue, through which AI is supported and whereby operational management may also become upskilled.

\subsection{3 'Mentally and physically behind on site' - AI exposure}

Another key theme gleaned from the analysis was the psychological impact of technology adoption, particularly AI as it can be at the expense of people. A manager provide some further insight into the psychological elements management encounter: 'They amass experience which gives them the edge, ability of a TM to look at a warehouse full of pallets to say, I need 15 people and 3 hours to shift that... that is purely experience. We put a system in and a report can tell you that. That's a massive hit for someone. That first barrier is biggest'. If AI and automation does not directly replace roles, it can certainly have a psychological impact, whereby operational operatives' skills and know-how may no longer be as relevant as previously. This is further witnessed here, as P.H posits: 'we have a conveyor in the middle.. But we don't use it. Because people are scared of it, they don't want to use it, they rather use man power'. P.H attributes the lack of engagement with the conveyor belt to reluctance and fear, while this is not AI, rather automation; it provides an understanding into warehouse mentality on a localised level. 
It was also evident that managers who had previous experience of AI technology were more articulate and forthcoming of AI implementation. P.H, a shift manager has amassed AI experience during his various previous roles, which was evident throughout his narratives: 'Unless you've seen it in action, and seen what it can do, you'll always be dismissive of it', and 'I've had exposure to a lot more than the guys here', thus, the lacklustre and negative responses from other management may be due to the lack of AI exposure and insight. The psychological aspects touched upon earlier were also experienced by P.H: 'I've seen it coming in and didn't believe it'll work, as I'm an old fashioned manager, boots on the ground' and 'we thought it would be rubbish'. Therefore, there is a need for alignment, with concurrent technological practices and management mentality.

\subsection{4 'If you don't handle the change, it will crash' - Change management}

The change management associated with adopting new technology was a theme extensively discussed by the project and implementation teams. Given the nature of operations within a warehouse, the operational management plays a crucial role in ensuring the change is handled and delivered effectively. P.C mentions: 'putting in a new desk, a new system, or AI, the process is the same.. The biggest thing you have to face is change management'. While the adoption of AI would impact warehouse operatives, it would also have implications for warehouse management, this was succinctly described by A.A: 'the management, who are tasked with managing the change for their teams, also require change management!' Thus, this highlights the nature and scope of managing change related to technology.

\subsection{5 'Our warehouses are not made of lego' - Flow and structural challenges.}

A senior warehouse manager highlights warehouse structure and processes as being a challenge within the warehouse, which may impede the potential of AI, S.A states: 'Some warehouses are off major motorways.. so there's issues of late or missing deliveries. Some older warehouses have a strange shape.. So it less about the system and more about the flow.' Similarly, P.H, highlighted the warehouse design and space being incompatible with AI: 'Space in here, the way the warehouse is laid out, it's like putting a Ferrari engine into a reliant regal, it'll topple over'. Similarly, R.B takes it further by suggesting AI should be operated in a purpose built warehouse: 'I believe warehouses need to be purpose built with AI or automation in mind. 'As such, layout changes need to be considered, to facilitate AI operations. However, the resources and costs associated with reconfiguring warehouse layout are high, and thus presenting a challenge from an AI viewpoint.

\subsection{Environment}

\subsection{1 'Let's not only catch up, but let's also take some advantages' - Competitive edge}

It is apparent that while the warehouse practises may be out-dated, with some operations still orderpicking on paper, their AI motivation is driven by their competitors. This is supported when the implementation manger outlines 'Everything I'm currently involved with is not a case of only trying to catch up... but also taking us to a place where we can take a big stride on top of that.' Similarly, the extent to which external pressures impacts the adoption of technology is further epitomised by a project manager, who similarly posits: 'it's a mammoth task, 2 in 1, let's not only catch up, but let's also take some advantages.' Therefore, the implementation and projects team understands that by investing in AI technology in the future, they can surpass competitors

Additionally external pressures were also identified, as S.H outlines: 'our external relationship certainly impacts how we do things, we're not as techy as them but I feel they'll motivate us into managing our warehouses differently.' The case organisation has recently entered in a wholesale partnership with several large online retailers and therefore S.H feels this may lead to sharing best practices between the organisations, particularly given that the trading partner organisations are technically advanced. 
In terms of barriers, shift manager R.B touched upon the risk of redundancies resulting from AI and mentioned: 'there's always going to be resistance from union/colleagues with the threat of redundancies'. therefore, external pressure from union groups may result in not completely embracing AI completely, as this has the potential to make many operatives redundant .A further barrier identified was the extent to which the transport team were able to cope with the increased output generated by the AI. In this regard, S.H mentions: 'We've got to see the impact at transport, if you squeeze a balloon, it'll pop at the other end. Therefore, what good is it, if we can't get products onto trailers!' Accordingly, the impact of this on the transport team and other areas of the business really do require consideration, thus potentially restricting how much of the 'AI dial can be turned up'.

\subsection{2'Days and shifts are (like) different companies' - Silo mentality}

The discrepancies in the ways of working and a lack of cohesion between day and night shifts was also identified as being a barrier, while also presenting opportunities from an AI perspective. S.A, mentions: 'day and nights are (like) two different companies, we don't operate using the same logic, approach of thinking, mainly because we have different challenges and priorities'. This was further emphasised by R.S: 'I won't say which [laughs], but one shift will break it [new tools, ways of working], and the other will spend time fixing it'. This therefore presents challenges for AI, as a disparity in skill-sets and support network between the shifts can hinder any warehouse wide AI progress. On the contrary, AI can bridge the differences between both shifts, as P.H, having experience of AI mentions: 'it's pointless having AI if it's not operating 24 hours a day, 7 days a week. So shift would have no choice but to work more seamlessly, transparently, sharing best practice and ways of working'. Therefore, in order for organisations to maximise benefits from automation and AI, it should be operated 24 hours. Thus allowing for a smoother transition and hand-over between both shifts.

\subsection{Perceived benefits}

\subsection{1 'I've seen it work, I've seen how it can work' - Perceived benefits}

From a warehouse operations viewpoint, travelling between locations involves cost, as M.B outlines: 'moving is dead time in warehouses, so when picking, moving between two places is dead, how can we control or shorten that?' accordingly, AI can help provide more control and essentially reduce the travelling costs in warehouses. It was evident that various members of the warehouse management were aware of the benefits of AI: 'We need to prove that we're delivering benefits with this first step. Can't be throwaway money'. The technology manager outlines that the 'phases' and current ways of working should present significant value to the organisation, and that by only doing so, other more significant technological advancements will be delivered.

While shift manager R.B highlights potential issues which may hinder AI adoption, he was also aware of the long-term benefits for the organisations. For instance, he outlined: 'AI can bring a cost benefit to the business once return of investment is achieved and of course service levels to customers would improve in the form of punctuality and accuracy.' While much of the insights were based on perception, P.H referred to his personal experiences when highlighting: 'I've seen it work; I've seen how it can work. I've seen shifts go from 100,000 to 150,000 units in the space of a year'.

It was also suggested that the containment of 'scope creep' is also imperative if AI benefits are to be experienced. A.A posits: 'you may introduce something to drive accuracy, someone, somewhere thinks we can stretch the project to include more than what was originally planned, with the endless opportunities with AI, the project has to be contained.' Consequently, AI potential can be maximised if the parameters of its project are not breached. 


\subsection{Discussion}

This research set out to answer research questions relating to the potential opportunities and barriers of warehouse AI adoption, by focusing on warehousing resources and human skillset. As a result, the findings provide varying perspectives on the readiness of AI adoption from a warehousing perspective. Through the utilisation of the extended TOE framework, the warehouse management of the case company were able to present their views on AI technology adoption from technology, organisation, environment and perceived benefits contexts. From a technological context, the excerpts of the organisational actors highlighted the significance of an organisations strategy and roadmap in the likelihood of AI adoption. The senior warehouse implementation manager outlined the importance of managing flexible planning techniques to support strategic and long-range planning, through matching short-term and long-term goals with specific technology solutions. As such, it is evident that success deployment of AI does not only depend on future technological strategising but also on existing infrastructure and capabilities which would allow for the technology to be switched on seamlessly. Kolbjørnsrud et al., (2017) also support this, highlighting that AI strategies should be specifically tailored to local and organisational conditions, as this is a facilitator of its eventual adoption. Therefore, in addressing the research questions, it is argued that flexible and open technical infrastructure, can be seen as an opportunity for AI readiness, whilst rigid, incompatible technical infrastructures are a barrier to warehouse $\mathrm{AI}$ adoption.

The analysis also revealed disparity in the mind-sets of management. While the implementation managers were fully supportive of potential AI technology acceptance, the operational managers displayed more pessimistic attitudes, thus in agreement with Kolbjørnsrud et al., (2017) and the findings from their studies which emphasised the least level of AI acceptance was from front-line managers. Interestingly, it was only the operational managers with previous experience and exposure to AI, who recognised the benefits of its adoption and were hopeful of its implementation. This is further emphasised when an operational manager posited that the warehouse, was behind, both mentally and physically, highlighting the incompatibility of the warehouse layout as well as the incongruence of colleague mind-sets hindering AI acceptance. This also resonates with Klump (2018), who argues logisticians tend to actively and trustfully collaborate with AI following three forms of resistance, AI competence, AI decisions and AI autonomy. It is argued that the operational managers with previous AI experience overcame such areas of resistance, hence their optimism towards AI adoption.

Interestingly, the warehouse management also emphasised the nature and culture of warehouse operations, particularly the tensions between day and night shifts as presenting a challenge for AI adoption. It was revealed that while the same operation was in place on both shifts, the processes and way in which shifts were operated differed, as a direct result of different challenges, dynamics, disparate support network and skill-sets across both shifts. Wu and Chui (2018) emphasises the role of human relationships and shared sense of identity within LSCM, referred to as social capital and its increasingly important role in reducing the likelihood of conflicts and its ability in advocating cooperative behaviour relating to shared vision, trust belief, and social ties between organisational actors. The warehouse manager with AI experience highlighted how AI adoption not only improves output and productivity, but also standardises processes and operations across disparate shifts, thus presenting an opportunity of bridging differences between the organisational actors' and their practices across both shifts.

\subsection{Theoretical Contributions}

A number of key theoretical implications are garnered as a result of this research. Firstly, through exploring the extant literature, this research identifies a shortfall in studies from within the body of Logistics and Supply Chain Management literature which places emphasis on the warehouse and 
warehousing operations. This is startling, particularly given the key role of warehousing and its implications within logistics and across the entire supply chain. Moreover, through synthesising the literature it was apparent from the scarce warehouse studies that focus has been towards design, technical factors and predominantly from an ergonomics perspective, thus presenting a gap in the warehousing literature which overlooks the dyadic relationship between humans and warehousing. This research also contributes to an existing body of academic literature which traditionally has been critiqued as lacking relevance for mangers, due to knowledge being produced which is neither relevant to managerial needs nor transferred correctly (Carter 2008). This, it is argued is a direct consequence of an over emphasis on quantitative methods and modelling within LSCM literature which fails to use real-case data, while also overlooking human factors (Davarzani and Norrman 2015). Accordingly, this research aimed at bridging this gap between theory and practice by providing practical insights and creating real knowledge that managers can use to better understand phenomena relating to that which impacts them.

Furthermore, majority of case study research conducted within warehousing contexts relate to warehousing operation strategy, which focus on high level decision- and policy-making activities (Davarzani and Norrman 2015) as opposed to aiming to understand managerial issues and factors involving technology adoption. Through consolidating the literature, this research fills this human-centric gap of warehousing studies by providing empirical insights underpinned by operational warehouse management. This research therefore consolidates the literature by providing insights into socio-technical aspects relating to warehousing. Furthermore, the research also presents a continuation of the TOE framework (Tornatzky \& Fleischer, 1990) for empirical research by extending the framework through the integration of an external construct in the form of 'perceived benefits'. As such, in line with the literature (Baker et al., 2012), it is argued that this framework provides appropriate lens for exploring technology adoption, particularly as the findings and insights from this research highlights the relevance and applicability of the TOE framework from within the context of state-of-art technology such as AI. In terms of representativeness of findings, the research provides common lessons for logistics and warehousing in general. Particularly given that all the participants for this research accounted for several decades of logistics and warehousing experience, stemming from a variety of companies, across various sectors including manufacturing, retail, healthcare and food production. Thus, the insights gleaned from the participants were also reflective of more collective, wider understanding and interpretation of the research dyad.

\subsection{Implications on Practice}

This research also presents some pertinent insights which hold practical relevance. As discussed in great detail in section 7, the findings of this research may prove highly important to organisations that are potentially exploring advanced, state-of-the-art technology such as AI in their distribution warehouses. The findings derived from this research contribute to improving the understanding of the current challenges associated with smart warehousing through the multi-faceted contexts of technology, organisation and environment, which are underpinned by human-centric, operational lenses. First and foremost, the findings will be of particular interest to Human Resources, as insights from this research can provide essential criterion for the recruitment activities of organisations that aspire to adopt AI technology within their logistic warehouses. Particularly as this research highlights that warehouse management possessing prior AI exposure and experience are more likely to engage and support any AI initiatives. Therefore, management acceptance is pivotal for organisations to maximise their chances of successful implementation of AI, with pre-existing knowledge and practical AI experience of managers being highly important in this process. This, therefore may prompt organisations that have AI on their future technology roadmap to recruit individuals possessing such attributes and mind-sets. It is also advised that organisations involve managers with previous AI experience at earlier stages of AI projects, thus allowing them to communicate the benefits and operational advantage of the AI technology to key operational stakeholders, particularly 
warehouse actors such as warehouse operatives, front-line managers and senior management. The findings indicate a disparity between the operational and technological skills of warehouse staff and managers, whereby they possess significant operational knowledge and skills, whilst lacking more technological skills. Therefore, it is recommended that operational benefits such as how AI may significantly impact pick-rate, enhanced accuracy and visibility and improve the overall operations are highlighted to managers as opposed to emphasising more technical aspects. As such approach would facilitate AI acceptance according to the skillset and mindsets of the operationally-orientated managers.

Another practical implication that can be considered from this research relates to the role of the warehouse layout in facilitating AI adoption. It is evident through the insights provided by various warehouse actors that the warehouse layout directly impacts the day-to-day productivity of warehousing operations, therefore should also be considered when exploring AI solutions for the warehouse. Management highlighted that although organisations have a real desire to adopt AI technology and automation within their warehouse, this may be hindered by the way in which the warehouse is laid out, with either ineffective flow or insufficient space allocation. More specifically, the managers expressed the need for either purpose-built warehouses, or warehouses that can be reconfigured with ease to compliment AI operations. Therefore, in addition to the managers skills-sets and attributes, organisations should explore their internal capabilities and facilities prior to committing to AI adoption within the warehouse. In addition to the implications, there any other significant learnings from this research, including technical infrastructure, transparency between strategy-makers and the warehouse management, senior management acceptance and the importance of standardising shift mentality for successful AI adoption.

\section{Conclusion}

The extant warehousing literature has been critiqued for lacking collaboration between researchers and practitioners, resulting from studies which lack relevance and application in real organisational settings. In summation, this research aimed at reducing the research and practice gap through acknowledging human factors and addressing pertinent, contemporary issues relating to warehouse management and operations. As such, the research provides practical insights which are of relevance to managers, their environment and skills. The findings reveal various opportunities and potential barriers of AI adoption within warehouse context. It was evident that the implementation and technology teams were optimistic about AI in the near future. Operational management who had previous experience of AI were also similarly expressive. However the findings reveal that management that have little or no experience of AI failed to perceive significant benefits from AI implementation. Furthermore, it was also apparent that limited insights into the organisations technology roadmap further contributed to their negative disposition of operational managers. The teams closest to the roadmap, i.e. the implementation and technology teams would also prefer more insights into the technological direction of the organisation, as this is something often cascaded down by senior, executive management. The findings also suggest that operational management lack skills in an increasingly digital world, to the extent that they were unable to identify the scope and capabilities of the current technologies in the warehouse, regardless of the fact this was their daily work settings. Therefore, making it difficult for them to acknowledge how AI can be switched on through the existing infrastructure. The opportunities of AI adoption were presented through existing infrastructure and the integrating capabilities of existing systems such as WMS. While substantial investment would be required both in terms of hardware and re-laying the warehouse, the change management and technology adoption were regarded as pertinent challenges of AI implementation. Therefore, through the findings and insights from operational management, this research improves the understanding of the current challenges associated with smart warehousing by acknowledging the critical role of organisational infrastructure, skills, mind-sets and AI exposure for AI technology adoption. 


\subsection{Limitations and future direction}

As with many studies, this research also has some limitations. It is worth noting that this research is based on 8 in-depth interviews, future warehousing research with a human-centric technological focus could expand the sample size and prove highly valuable in enhancing our understanding of sociotechnical factors within operational warehouse settings. In addition, it is acknowledged that the single case study does not allow for broader generalisation. While this approach provided an in-depth account of the phenomenon in question, and covered important issues of human factor in warehousing context, further investigations are required to evaluate the wider implications of the human-technology warehousing dyad. As a result of the findings and discussions, this research further recommends the following two research propositions to be explored in future research:

\section{Proposition 1:}

The technology readiness level of AI for a logistics warehouse is dependent on the level of previous AI exposure of the management.

\section{Proposition 2:}

The shortage in the skills and mind-set of warehouse management significantly diminishes the opportunities presented by AI technology.

\section{References}

Aboelmaged, M. G. (2014). Predicting e-readiness at firm-level: An analysis of technological, organizational and environmental (TOE) effects on e-maintenance readiness in manufacturing firms. International Journal of Information Management, 34(5), 639-651.

Ajzen, I. (1985) From Intentions to Actions: A Theory of Planned Behavior. Berlin: Springer.

Angeles, R. (2009). Anticipated IT infrastructure and supply chain integration capabilities for RFID and their associated deployment outcomes. International Journal of Information Management, 29(3), 219-231

Arooj, A., Mufti, M. \& Jamal, H. (2011). Collaborative Communication of Active RFID Tags for Warehouse Asset Management, IJCSNS, 11 (2): 39-46.

Autor, D. H (2015) 'Why are there still so many jobs? The history and future of workplace automation, Journal of Economic Perspectives, 29 (3)

Aziz, Z.A., Razak, R.C., Yacoob, M.R., Hussin, N.S.N. \& Razmin, N.H.M (2016). Do Technological and Organizational Innovation Have Significant Influences on the Logistics Performance? International Journal of Business and Management Invention, 5 (11), 55-62

Baker, J. (2012). The technology-organization-environment framework. In Information Systems Theory (pp. 231-245). Springer New York

Bhattacherjee A. (2012) Social Science Research: Principles, Methods, and Practices.

Bhuptani, M., \& Moradpour, S. (2005). RFID Field Guide: Deploying Radio Frequency 
Identification Systems. Upper Saddle River, NJ: Prentice Hall

Bose, I. \& Pal, R. (2005). "Auto-ID: Managing anything, anywhere, anytime in the supply chain. Communications of the ACM 48(8): 100-106.

Boysen, N., Briskorn, D., \& Emde, S. (2017). Sequencing of picking orders in mobile rack warehouses. European Journal of Operational Research, 259(1), 293-307.

Braun, V. and Clarke, V. (2006) Using thematic analysis in psychology. Qualitative Research in Psychology, 3 (2). pp. 77-101. ISSN 1478-0887

Byrne P.M., \& Markham W.J. (1991), Improving quality and productivity in the logistics process: Achieving customer satisfaction breakthroughs, Oak Brrok, Council of Logistics Management.

Brown, I., \& Russell, J. (2007). Radio frequency identification technology: An exploratory study on adoption in the south african retail sector. International Journal of Information Management, 27(4), 250-265.

Brynjolfsson, E,. Rock, D, Syverson, C. (2017) Artificial intelligence and the modern productivity paradox: A clash of expectations and statistics, NBER working paper

Carter, C. R. (2008). knowledge production and knowledge transfer: Closing the researchpractice gap. Journal of Supply Chain Management, 44(2), 78-82.

Chan, F.T.S. \& Kumar, V. (2009) A hybrid TSSA algorithm based approach to solve warehouse scheduling problems. International Journal of Production Research, 47 (4), 919940.

Chan, F., \& Chan, H. K. (2011). Improving the productivity of order picking of a manual-pick and multi-level rack distribution warehouse through the implementation of class-based storage. Expert Systems with Applications, 38, 2686- 2700.

Chan, L. K., \& Cheng, C. Y. (2012). Joint Order Batching and Picker Routing Using Twophased Algorithm. In Proceedings of the Asia Pacific Industrial Engineering \& Management Systems Conference, eds.

Chau, P. Y. \& Tam, K. Y. (1997). Factors affecting the adoption of open systems: An exploratory study. MIS Quarterly, 21(1), 1-24

Chaysin, P., Jirapun, D. \& Nopphon, T. (2016) . Survey on Available Methods to Evaluate IT Investment. Electronic Journal Information Systems Evaluation,19 (1): 72-82.

Chincholkar, A.K., Krishnaiah Chetty O.V. \& Kuppuswamy, G. (1994) Analysis of an automated storage and retrieval system using stochastic coloured Petri Nets Advances in Modelling \& Analysis, 44 (3) 19-30

Chow, H. K. H., Choy, K. L., \& Lee, W. B. (2007). A dynamic logistics process knowledgebased system - an RFID multi-agent approach. Knowledge-Based Systems, 20(4), 357-372.

Chow, H. K. H., Choy, K., Lee, W., \& Chan, F. T. S. (2005). Design of a knowledge-based logistics strategy system. Expert Systems with Applications, 29, 272-290. 
Choy, K. L., Gunasekaran, A., Lam, H. Y., Chow, K. H., Tsim, Y. C., Ng, T. W., \& Lu, X. A. (2014). Impact of information technology on the performance of logistics industry: the case of Hong Kong and Pearl Delta region. Journal of the Operational Research Society, 65(6), 904916

Coyle, J. J., E. J. Bardi \&, Langley, C. J. (1996) The Management of Business Logistics. South Western College Publishing

Cullen, J., Tsamenyi, M., Bernon, M., \& Gorst, J. (2013). Reverse logistics in the UK retail sector: A case study of the role of management accounting in driving organisational change.Management Accounting Research, 24(3), 212-227

Curry, G. L., Peters, B. A., \& Lee, M. (2003). Queueing network model for a class of material-handling systems. International Journal of Production Research, 41(16), 39013920.

David, P.A. (1990) The Dynamo and the Compute: An Historical Perspective on the Modern Productivity Paradox. The American Economic Review, 80(2) 355:61

Davidsson, P., Henesey, L., Ramstedt, L., Törnquist, J., Wernstedt, F., Sektionen för teknik, . . Blekinge Tekniska Högskola. (2005). An analysis of agent-based approaches to transport logistics. Transportation Research Part C, 13(4), 255-271.

Davis Jr., F. D. (1986) A Technology Acceptance Model for Empirically Testing New Enduser Information Systems: Theory and Results. PhD, Massachusetts Institute of Technology

De Koster, R., Le-Duc, T. \& Roodbergen K. F. (2007). Design and Control of Warehouse Order Picking: a Literature Review. European Journal of Operational Research, 182: 481501.

Derhami, S., Smith, J. S., \& Gue, K. R. (2017;2016). Optimising space utilisation in block stacking warehouses. International Journal of Production Research, 55(21), 6436-17.

Dhillon, G. (2005) Gaining benefits from IS implementation: Interpretations from case studies. International Journal of Information Management, 25(6), 502-515.

Domingos, P. (2012). A few useful things to know about machine learning. Communications of the ACM, 55(10), 78-87.

Dwivedi, Y. K., Rana, N. P., Jeyaraj, A., Clement, M., \& Williams, M. D. (2017). Reexamining the unified theory of acceptance and use of technology (UTAUT): Towards a revised theoretical model. Information Systems Frontiers, doi:10.1007/s10796-017-9774-y

Džubáková, M., \& Kopták, M. (2017). Work standardisation in logistics processes. Quality Innovation Prosperity, 21(2), 19.

ELA/AT Kearney (2005), Excellence in Logistics 2004: Differentiation for Performance, ELA, Brussels.

Etikan, I., Alkassim, R., \& Abubakar, S. (2016). Comparison of Snowball Sampling and Sequential Sampling Technique. Biometric \& Biostatistics International Journal, 3(1), 1-2. Faber, N., de Koster, M. B. M., \& Smidts, A. (2013). Organizing warehouse management.International Journal of Operations \& Production Management, 33(9), 12301256. 
Flint, D. J., Larson, E., Gammelgaard, B., \& Mentzer, J. T. (2005). Logistics innovation: a customer value-oriented social process. Journal of Business Logistics, 26(1), 113-147

Frazelle, E.H. (2002), World-Class Warehousing and Material Handling, McGraw-Hill, New York, NY.

Frey, C. and J. Hawksworth (PwC, 2015): http://www.pwc.co.uk/assets/pdf/ukeo-regionalmarch-2015.pdf

Gibbs, L.J. \& Kraemer, K.L. (2004) A cross-country investigation of the determinants of scope of e-commerce use: An institutional approach, Electronic Markets, 14(2) 124:137

Govindan, K., Cheng, T. C. E., Mishra, N., \& Shukla, N. (2018). Big data analytics and application for logistics and supply chain management. Transportation Research Part E, 114, 343-349.

Gu, J., Goetschalckx, M., \& McGinnis, L. F. (2010). Research on warehouse design and performance evaluation: A comprehensive review. European Journal of Operational Research, 203(3), 539-549.

Gu, J., Goetschalckx, M., \& McGinnis L. F. (2007). Research on Warehouse Operation: A Comprehensive Review. European Journal of Operational Research 177 (1): 1-21.

Halldórsson, Á., \& Aastrup, J. (2003). Quality criteria for qualitative inquiries in logistics.European Journal of Operational Research, 144(2), 321-332.

Hartono, E., Li, X., Na, K., \& Simpson, J. T. (2010). The role of the quality of shared information in interorganizational systems use. International Journal of Information Management, 30(5), 399-407

Hassan, M., Ali, M., Aktas, E., \& Alkayid, K. (2015). Factors affecting selection decision of auto-identification technology in warehouse management: An international delphi study. Production Planning \& Control, 26(12), 1025-1049

Hennelly, P., Graham, G. Srai, J., \& Meriton, R. (2017). Do makerspaces represent scalable production models of community based redistributed manufacturing, Production Planning \& Control. Forthcoming.

Ho, L.H., \& Chang, P.Y. (2015). Innovation capabilities, service capabilities and corporate performance in logistics services. International Journal of Organizational Innovation, 7(3), 24-33.

Holtel S (2016) Cognitive literality in the age of the thinking machine. In Sauter W, Erpenbec J, ediotors, Handbook of Competence. Stuttgart Schaffler-Poeschel; in print

Holtel, S. (2014). More than the end of Information overflow. How IBM Watson will turn doen our view on Information Appliances. In: Seoul.

Holtel, S. (2015). From computer to centaur-Cognitive tools turn the rules upside down. KMWorld Magazine 24(2) 
Houé, T., \& Murphy, E. (2017;2016;). A study of logistics networks: The value of a qualitative approach. European Management Review, 14(1), 3-18.

Hsieh, S. (1998). A petri-net-based structure for AS/RS operation modelling. International Journal of Production Research, 36(12), 3323-3346

Hsu, P.F., Kraemer, K.L. \& Dunkle, D. (2006). Determinants of e-business use in us firms, International Journal of Electronic Commerce, 10(4) 9-45.

Huber, N., K. Michael, \& L. McCathie. (2007) .Barriers to RFID adoption in the supply chain. Paper presented at IEEE RFID Eurasia, Istanbul, September 5-6.

Huemer, L. (2012). Unchained from the Chain: Supply Management from a Logistics Service Provider Perspective. Journal of Business Research, 65 (2): 258-264.

Hwang, H., C. Ku, D. C. Yen, \& C. Cheng. (2004). Critical Factors Influencing the Adoption of Data Warehouse Technology: A Study of the Banking Industry in Taiwan. Decision Support Systems, 37 (1): 1-21.

Jawandhiya, P. (2018) Hardware Design for Machine Learning, International Journal of Artificial Intelligence and Applications, 9 (1) 63:84.

Jazairy, A, Johannes L, \& Haartman, R. (2017) Improving Logistics Performance in Cross Border 3PL Relationships. International Journal of Logistics Research and Applications 20 (5): 491-513.

Jedermann, R., Lang, W. (2008): The benefits of embedded intelligence - tasks and applications for ubiquitous computing in logistics. In C. Floerkemeier and et al., editors, Proceedings of The Internet of Things. First International Conference, number 4952

Jia, Q., Guo, Y., \& Barnes, S. J. (2017). Enterprise 2.0 post-adoption: Extending the information system continuance model based on the technology-organization-environment framework. Computers in Human Behavior, 67, 95-105.

Karagiannaki, A., D. Papakiriakopoulos, \& C. Bardaki. (2011).Warehouse Contextual Factors Affecting the Impact of RFID. Industrial Management \& Data Systems, 111 (5):714-734.

Keller, S. B., Savitskie K., Stank, T. P., Lynch, D. F. \& Ellinger, A. E. (2002) A summary and analysis of multi-item scales used in logistics research. Journal of Business Logistics, 23: 83-119.

Khajavi, S. H., \& Holmström, J. (2015). Manufacturing Digitalization and Its Effects on Production Planning and Control Practices. In IFIP International Conference on Advances in Production Management Systems, 179-185. Springer.

Kiefer, A.W. \& Novack, R.A. (1999), "An empirical analysis of warehouse measurement systems in the context of supply chain implementation", Transportation Journal, Vol. 38 No. 3, pp. 18-27.

Kim, S., \& Garrison, G. (2010). Understanding users' behaviors regarding supply chain technology: Determinants impacting the adoption and implementation of RFID technology in south korea. International Journal of Information Management, 30(5), 388-398. 
Kim, W. R., Kim, N., \& Chang, Y. S. (2016). A study on the control of an automatic picking system (APS) in a warehouse. Assembly Automation, 36(4), 388-397.

Klumpp, M. (2018). Automation and artificial intelligence in business logistics systems: Human reactions and collaboration requirements. International Journal of Logistics Research and Applications, 21(3), 224-242.

Knapp, G.M. \& Wang H.P. (1992) Modeling of automated storage/retrieval systems using Petri nets. Journal of Manufacturing Systems, 11 (1) 20-29

Kolbjørnsrud, V., R. Amico, and R. J. Thomas. (2017) "Partnering with AI: How Organizations can win Over Skeptical Managers." Strategy \& Leadership 45 (1): 37-43.

Korobkov, E. (2014). Warehouse order-picking process. review. Science and Education of the Bauman MSTU, 15(3)

Kowalski M., Zelewski S., Bergenrodt D., \& Klupfel H (2012) Application of new techniques of artificial intelligence in logistics: an ontologydriven case-based reasoning approach // Proceedings of European Simulation and Modelling Conference 2012. Essen, Germany

Kshetri, N. (2018). 1 Blockchain's roles in meeting key supply chain management objectives. International Journal of Information Management, 39, 80-89.

Kuan, K. K. Y., \& Chau, P. Y. K. (2001). A perception-based model for EDI adoption in small businesses using a technology-organization-environment framework. Information \& Management, 38(8), 507-521.

Kumar, V., Mishra, N., Chan, F. T. S., \& Verma, A. (2011). Managing warehousing in an agile supply chain environment: An F-AIS algorithm based approach. International Journal of Production Research, 49(21), 6407-6426

Lambert, D.M., Stock, J.R., Ellram, L.M. (Eds.), 1998. Fundamentals of Logistics Management. McGraw-Hill, Singapore.

Lang, N., Moonen, H., Srour, F.J. and Zuidwijk, R.A. (2008). Multi-agent systems in logistics: A literature and state-of-the-art review. ERIM Report Series, Reference No. ERS2008-043-LIS

Langley, C.J., \& Holcomb, M.C. (1992). Creating logistics customer value. Journal of Business Logistics, 13, 1-27.

Laosirihongthong, T., P. Punnakitikashem, \& D. Adebanjo. (2013). Improving Supply Chain Operations by Adopting RFID Technology: Evaluation and Comparison of Enabling Factors. Production Planning \& Control, 24 (1): 90-109.

Lee, H.-D., B.-K. Lee, W.-S. Kim, J.-S. Han, K.-S. Shin, and C.-S. Han (2014) 'HumanRobot Cooperation Control Based on a Dynamic Model of an Upper Limb Exoskeleton for Human Power Amplification.” Mechatronics 24: 168-176

Lee, C. K. M., Lv, Y., Ng, K. K. H., Ho, W., \& Choy, K. L. (2018). Design and application of internet of things-based warehouse management system for smart logistics. International Journal of Production Research, 56(8), 2753. 
Leimeister, S., Leimeister, J. M., Knebel, U., \& Krcmar, H. (2009). A cross-national comparison of perceived strategic importance of RFID for CIOs in germany and italy.International Journal of Information Management, 29(1), 37-47.

Lerher, T., Potrč, I., Šraml, M., \& Tollazzi, T. (2010). Travel time models for automated warehouses with aisle transferring storage and retrieval machine. European Journal of Operational Research, 205(3), 571-583

Lin, J. (2011) Technological adaptation, cities, and new work. Review of Economics and Statistics 93 (2)

Liviu, I., T. Ana-Maria, \& C. Emil. (2009). Warehouse Performance Management - A Case Study. Annals of Faculty of Economics 4 (1): 307-312.

Machado, A., \& Sellitto, M. A. (2011). Benefits of the implementation and use of a warehouse management system in a distribution center. Revista Produção Online, 12(1), 4672.

Matta, V., Koonce, D., Jeyaraj, A. (2012) Initiation, experimentation, implementation of innovations: The case for radio frequency identification systems International Journal of Information Management, 32 (2) 164-174

Mejia, J. (2014). logistics intelligence. Latin Trade, 22(6), 36.

Min, H. (2010). Artificial intelligence in supply chain management: theory and applications. International Journal of Logistics Research and Applications, 13(1), 13-39.

Mishra, N., Kumar, V., Kumar, M., Kumar, N., \& Tiwari, M. K. (2011). Addressing lot sizing and warehousing scheduling problem in manufacturing environment. Expert Systems with Applications, 38(9), 11751-11762.

Moore, T. D. (1990). Logistics intelligence: The first step in operational sustainment? Army command and general staff coll fort Leavenworth ks school of advanced military studies.

Myers, M. B., Griffith, D. A., Daugherty, P. J., \& Lusch, R. F. (2004). Maximizing the human capital equation in logistics: Education, experience, and skills. Journal of Business Logistics, $25,211-232$.

Ocado solutions UK. What we do: Ocado smart platfor m (2018). https://ocadosolutions.com/ Accessed 13 June 2018.

Oláh, J., Karmazin, G., Pető, K., \& Popp, J. (2017). Information technology developments of logistics service providers in Hungary. International Journal of Logistics Research and Applications, 1-13. https://doi.org/10.1080/13675567.2017.1393506

Oliveira, T., \& Martins, M. F. (2011) Literature Review of Information Technology Adoption Models at Firm Level. Electronic Journal of Information Systems Evaluation 14 (1): 110-121.

Orlikowski, W., \& Gash, D. (1994). Technological frames: Making sense of information technology in organizations. ACM Transactions on Information Systems (TOIS), 12(2), 174207. 
Pan, L., J. Z. Huang, \& Chu, S. C. K.. (2011). Order Batching and Picking in a Synchronized Zone Order Picking System. In: Proceedings of the IEEE International Conference on Industrial Engineering and Engineering Management, Singapore, 156-160.

Patro, C. S., \& Raghunath, K. M. K.. (2015). Impetus to Supply Chain Decisions with IT Tools: An Empirical Study. International Journal of Enterprise Information Systems, 11 (3): $52-67$.

Pickering (2017). Take a look inside Alibaba's smart warehouse where robots do $70 \%$ of the work. Business Insider UK. http://uk.businessinsider.com/inside-alibaba-smart-warehouserobots-70-per-cent-work-technology-logistics-2017-9 /Accessed 4 May 2018

Pickering (2017). This Amazon-style warehouse robot can climb massive shelving units to stack 400 parcels an hour. http://uk.businessinsider.com/exotec-ai-shelf-climbing-robotprocess-warehouse-orders-amazon-alibaba-2017-12 / Accessed 4 May 2018.

Poon, T. C., K. L. Choy, F. T. S. Chan, \& Lau, H. C. W. (2011). A Real-time Production Operations Decision Support System for Solving Stochastic Production Material Demand Problems. Expert Systems with Applications, 38 (5): 4829-4838.

Porter, M.E., \& Heppelmann J.E. (2015) How smart, connected products are transforming competition. Harvard Business Review, 93, October, 96-114

PricewaterhouseCooper. Will robots steal our jobs? The potential impact of automation on the UK and other major economies. (2017). https://www.pwc.co.uk/economicservices/ukeo/pwcukeo-section-4-automation-march-2017-v2.pdf / Accessed 29 May 2018.

Quetti, C., F. Pigni, \& A. Clerici. (2012). Factors Affecting RFID Adoption in a Vertical Supply Chain: The Case of the Silk Industry in Italy. Production Planning \& Control, 23 (4): $315-531$.

Rogers, E. M. (1995) Diffusion of Innovations. New York: The Free Press

Roodbergen, K. J., \& Vis, I. F. A. (2009). A survey of literature on automated storage and retrieval systems. European Journal of Operational Research, 194(2), 343-362.

Rouwenhorst, B., B. Reuter, V. Stockrahm, G. van Houtum, R. Mantel, \& W. Zijm. (2000). Warehouse Design and Control: Framework and Literature Review. European Journal of Operational Research, 122 (3): 515-533.

Rubrico, J. I. U., Ota, J., Tamura, H., Akiyoshi, M., \& Higashi, T. (2004) Route generation for warehouse management using fast heuristics. In: Proceedings of IEEE/RSJ international conference on intelligent robots and systems, 28 September-2 October, Sendai, Japan, 20932098.

Sabherwal, R., \& Jeyaraj, A. (2015). Information technology impacts on firm performance: An extension of kohli and devaraj. MIS Quarterly, 39(4), 809.

Sachan, A. \& Datta, S. (2005) Review of supply chain management and logistics research. International Journal of Physical Distribution and Logistics Management, 35: 664-705. 
Sarac, A., N. Absi, \& Dauzère-Pérès, S. (2010). A Literature Review on the Impact of RFID Technologies on Supply Chain Management. International Journal of Production Economics, 128 (1): 77-95.

Schwarz, A. \& Chin, W. (2007). Looking forward: Toward an Understanding of the Nature and Definition of IT Acceptance. . Journal of the Association for Information Systems, 8 (4), 230- 243.

Seidmann, A. (1988). Intelligent control schemes for automated storage and retrieval systems. International Journal of Production Research, 26(5), 931-952.

Seifermann, S., Böllhoff, J., Metternich, J., and Bellaghnach, A. (2014) "Evaluation of Work Measurement Concepts for a Cellular Manufacturing Reference Line to Enable Low Cost Automation for Lean Machining," Procedia CIRP, 17, 588-593

Siror, J. K., Huanye, S., \& Dong, W. (2011). RFID based model for an intelligent port.Computers in Industry, 62(8), 795-810

Stiglitz, Joseph E. (2014). "Unemployment and Innovation." NBER Working Paper No. 20670.

Stoica, D. Song, R. A. Popa, D. Patterson, M. W. Mahoney, R. Katz, A. D. Joseph, M. Jordan, J. M. Hellerstein, J. E. Gonzalez (2017) "A berkeley view of systems challenges for ai," arXiv preprint arXiv: 1712.05855

Sze, V., Yu-Hsin Chen, Emer, J., Suleiman, A., Zhang, Z. (2017) Hardware for Machine Learning: Challenges and Opportunitie, CICC

Tompkins, J. A., et al., (2003). Facilities Planning. New York: Wiley.

Tompkins, J.A., White, J.A., Bozer, Y.A., Frazelle, E.H., Tanchoco, J.M.A. (2003) Facilities Planning. John Wiley \& Sons, NJ.

Tornatzky, L. G., \& M. Fleischer. (1990) The Process of Technology Innovation. Lexington, MA: Lexington Books

Varoutsa, E., \& Scapens, R. W. (2015). The governance of inter-organisational relationships during different supply chain maturity phases. Industrial Marketing Management, 46(3), 6882.

Venkatesh, V. and Bala, H. (2008). Technology Acceptance Model 3 and a Research Agenda on Interventions. Decision Science, 39 (2), 273-312.

Venkatesh, V., \& Davis, F. D. (2000). A Theoretical Extension of the Technology Acceptance Model: Four Longitudinal Field Studies. Management Science, 46 (2), 186-204

Venkitasubramony, R., \& Adil, G. K. (2017). Design of an order-picking warehouse factoring vertical travel and space sharing. The International Journal of Advanced Manufacturing Technology, 91(5), 1921-1934

Vieira, C. L. d. S., Coelho, A. S., \& Luna, M. M. M. (2013). ICT implementation process model for logistics service providers. Industrial Management \& Data Systems, 113(4), 484505 . 
Vijayaraman, B. S., \& Osyk, B. A. (2006). An empirical study of RFID implementation in the warehousing industry. The International Journal of Logistics Management, 17(1), 6-20

Wagner, S. M., \& Sutter, R. (2012). A qualitative investigation of innovation between third-party logistics providers and customers. International Journal of Production Economics, 140(2), 944-958

Wang, Y., Caron, F., Vanthienen, J., Huang, L., \& Guo, Y. (2014). Acquiring logistics process intelligence: Methodology and an application for a chinese bulk port. Expert Systems with Applications, 41(1), 195.

Wang, Y., Wang, Y., \& Yang, Y. (2010). Understanding the Determinants of RFID Adoption in the Manufacturing Industry. Technological Forecasting and Social Change, 77 (5): 803815 .

Watson, J. P., Rana, S. Whitley, L. D., \& Howe A. E. (1999) The impact of approximate evaluation on the performance of search algorithms for warehouse scheduling. Journal of Scheduling, 2(2):79-98

Wen, W. (2010). An intelligent traffic management expert system with RFID technology.Expert Systems with Applications, 37(4), 3024-3035.

Williams, M. D., Rana, N. P., \& Dwivedi, Y. K. (2015). The unified theory of acceptance and use of technology (UTAUT): A literature review. Journal of Enterprise Information Management, 28(3), 443-488.

Wu, Y. (2012) "A Dual-Response Strategy for Global Logistics Under Uncertainty: A Case Study of a Third-Party Logistics Company." International Transactions in Operational Research 19 (3): 397-419.

Wu, I., \& Chiu, M. (2018). Examining supply chain collaboration with determinants and performance impact: Social capital, justice, and technology use perspectives. International Journal of Information Management, 39, 5-19.

Yang, C.-C., Marlow, P. B., \& Lu, C.-S. (2009). Assessing resources, logistics service capabilities, innovation capabilities and the performance of container shipping services in Taiwan. International Journal Production Economics, 122(1), 4-20.

Zhou, T., Lu, Y. B., \& Wang, B. (2010). Integrating TTF and UTAUT to explain mobile banking user adoption. Computers in Human Behaviour, 26(4), 760-767

Zhu, X., Mukhopadhyay, S. K., \& Kurata, H. (2012). A review of RFID technology and its managerial applications in different industries. Journal of Engineering and Technology Management, 29(1), 152-167.

Żuchowski, W. (2016). The impact of e-commerce on warehouse operations. Logforum, 12(1) 